\title{
Breaking with Norms of Masculinity: Men Making Sense of Their Experience of Sexual Assault
}

\author{
Charlotte C. Petersson ${ }^{1} \mathbb{D} \cdot$ Lars Plantin $^{1}$
}

Published online: 7 January 2019

(c) The Author(s) 2019

\begin{abstract}
In recent years, the sexual assault of males has received growing attention both in the research literature and among the public. Much of the research has focused on documenting prevalence rates or the psychological consequences of male sexual assault. However, this article aims to understand how men, as gendered, embodied and affective subjects, make sense of their experiences of sexual assault. In-depth interviews with ten adult males who have experienced sexual assault have been analyzed using a phenomenological approach in order to learn more about their lived and gendered experience. Four themes emerged from the analysis: (a) conflicting feelings and difficult conceptualizations, (b) re-experiencing vulnerability, (c) emotional responses and resistance, and (d) disclosure and creativity. The findings suggest that the ways in which men navigate norms of masculinity shape the way they understand, process and articulate their lived experience of sexual assault. As a way of coping with the experience and of healing from a past that is still present, the study participants perform an alternative masculine identity.
\end{abstract}

Keywords Male sexual assault $\cdot$ Masculinity $\cdot$ Embodied experience $\cdot$ Phenomenology

\section{Introduction}

Sexual violence is a widespread phenomenon and a major public health issue both internationally (WHO 2013) and in Sweden (NCK 2014). Female sexual assault is a well-established area of research given its rate of prevalence. In contrast, male sexual assault receives less attention, but awareness is growing, particularly in light of the recent revelations of child sexual abuse by Catholic priests. Previous research on male sexual assault has often focused on specific forms of sexual violence, such as child sexual abuse (Alaggia and Millington 2008; Dube et al. 2005; Fergusson et al. 1996) or sexual assault in institutional settings (Scarce 1997; Wooden and Parker 1982) and in areas of armed conflict (Clark 2017; Sivakumaran 2007). Regardless of gender, studies show that sexual assault has a profound impact on the psychosocial well-being of the victims, who report suffering from anxiety, depression, post-traumatic stress disorder, sexual dysfunction, self-harming behavior and suicidality (e.g. Mouilso

Charlotte C. Petersson

chchpeterson@gmail.com

1 Department of Social Work, Malmö University, 20506 Malmö, Sweden et al. 2010; Pegram and Abbey 2016; Peterson et al. 2011; Tewksbury 2007; Yuan et al. 2006). Although symptoms are documented as being similar, the cultural construction of gender has been identified as playing a central role in the way sexual assault is experienced, processed and manifested (Draucker 2003; Getz 2011). Norms of masculinity serve to ascribe blame to sexually assaulted men, silencing the victims and hindering them from seeking formal support services (Walker et al. 2005). Rather than reducing the experience of sexual assault to various psychopathological impacts, this phenomenological study conducted in Sweden focuses on the lived experience of adult men who have been sexually assaulted in childhood and/or in adulthood. By reflecting on their lives and the role that their history of sexual assault has played, the aim of the study is to understand how men make sense of their experience of sexual assault as gendered, embodied and affective subjects. How do notions of gender affect the way men understand, process and articulate their experiences of sexual assault? The narratives of the participants in this research offer insights into the lived experience of sexually assaulted men. These insights provide useful information for therapists, social workers and other professionals in their work to counsel and support sexually assaulted men. 


\section{Background}

The term sexual assault, including child sexual abuse, refers to a form of sexual violence that ranges from unwanted touching to rape. Prevalence rates for male sexual assault indicate that such violations occur to a significant extent (Davies 2002; Larsen and Hilden 2016; Tewksbury 2007). According to a national survey carried out by the National Centre for Knowledge on Men's Violence Against Women (NCK) in Sweden, 4\% of adult males have experienced completed or attempted forced sexual intercourse during childhood and $1 \%$ during adulthood. This means that, in Sweden, approximately 171,000 men are living with the experience of severe forms of sexual assault (NCK 2014). An annual national survey shows that the number of male rapes reported to the Swedish police is gradually increasing, and in 2017, the total number of reported cases reached 559 (Brå 2018).

Feminists have long argued that domestic and sexual violence is a manifestation of power and control (Brownmiller 1975; Dobash and Dobash 1979). Sexual assault is characterized by unilateral and coercive acts of violence committed without a person's consent, against someone unable to provide consent or against children. It includes at least two people, a perpetrator and a victim, concepts which in the current article are used only as situatedaction terms and do not refer to identity (Renoux and Wade 2008). Violence is a tool used by the perpetrator to establish and control relations of power, challenging the subjectivity of the victim. Callaghan et al. (2016) describe the establishment of power and the loss of subjectivity as two interrelated processes. As the power and control of the perpetrator increases, the world of the victim, including his or her notion of self within that world, decreases, and vice versa. Therefore, many researchers and therapists focus on how victims resist violence, openly or secretly, in the moment the violence occurs or even several years later (Kelly 1988; Scott 1990; Wade 1997). Moreover, studies suggest that men and women do not experience violence in similar ways. Different power and gender relations inherent in the context in which the violence occurs shape the two genders' respective experiences of violence (Sundaram et al. 2004), including how these experiences are processed, manifested and articulated long after the event (Draucker 2003; Getz 2011). The experience of sexual assault appears to be particularly difficult for men, as it undermines their own sense of power and control and challenges their masculine identity (Kia-Keating et al. 2005).

Connell $(1995,2000,2005)$ has investigated gender relations among men by applying a critical feminist analysis and has found that relationships between men or groups of men are hierarchically organized. Hegemonic masculinity ideals characterize real men in western contexts as strong, sexually assertive, heterosexual, dominant, active and in control of their emotions. Violence is an integral part of this masculinity and a means of sustaining dominance or achieving status. These ideals are institutionalized during the childhood years and in family and sexual relationships (Connell 1995; Messerschmidt 1999). Men who express emotion and vulnerability within the context of hegemonic masculinity are showing weakness, and weakness is associated with femininity. According to Connell (1995, 2005), white, middle-class, heterosexual men set the normative standards of hegemonic masculinity, but only a few are able to practice it; others may in fact protest, contest and resist it.

Being a male victim of sexual assault stands in contrast to hegemonic or conventional norms of masculinity. According to these gender norms, men are expected to seek and actively engage in sexual activity. If they are attacked, they are also expected to be able to defend themselves. Therefore, sexually assaulted men come to be seen as feminized victims and sexual objects: damaged, weak, powerless and helpless in the face of sexual violence (Kwon et al. 2007). Conventional masculinity norms generate self-blaming attributions that shape and influence how men respond to the experience of sexual assault. As many studies have problematized, men rarely self-report or disclose their victimization (Davies 2002; Mezey and King 1989; Peterson et al. 2011; Turchik and Edwards 2012; Walker et al. 2005). This results in underreporting, late reporting and a lack of helpseeking behavior, which in turn mean that men are also less likely to receive formal support services, and instead rely on informal networks (Freeland et al. 2016). As a result, sexually assaulted men express greater difficulties in coping with and finding solutions in relation to experiences of sexual assault. Studies suggest that male victims are more likely than female victims to express anger and hostility and to withdraw from social interaction (Peterson et al. 2011; Tewksbury 2007). Men also run a higher risk of abusing alcohol and other substances as a way of trying to cope with or suppress difficult memories and feelings (Alaggia and Millington 2008; Ratner et al. 2003). In fact, following exposure to violence and power, some men react by overemphasizing masculine attributes, for example by displaying hyperactive, hypersexual, overcontrolling, aggressive or violent behavior (Lisak 1995). Many male victims of sexual assault experience long-term confusion regarding their sexual identity and orientation, questioning whether they are gay, why they attract other men or why they did not want sex with a woman who wanted to have sex with them (Davies 2002; Mezey and King 1989; Scarce 1997; Walker et al. 2005). According to a study by Struckman-Johnson and StruckmanJohnson (1994), male sexual assault victims tend to report negative experiences mainly when the perpetrator is male. 
Since gender norms encourage men to seek and engage in sexual activities with women in any situation, sexual violations by female perpetrators may rather be interpreted as sexual experiences. In one study, men reported sexual assaults perpetrated by women as a "moderately upsetting" experience (Krahé et al. 2003, p. 169).

Notions of masculinity are not fixed but are multiple and flexible (Connell 2005). The male responses to experience of sexual assault noted in many studies may be common in contexts characterized by more conventional views about sexuality and gender. As ideals of masculinity change and become more diverse, so too may the perceptions of those who have experienced sexual assault. An alternative and more comprehensive notion of how to be manly in contemporary society has been reported in various contexts in which the culture of homophobia and sexism is on the decline and where it is also becoming more common to show emotion (Anderson 2005; McQueen 2017; Rafanell et al. 2017). Contrasting, conflicting and competing forms of masculinity can be encouraged, created and supported by organizations, institutions and culture (Anderson 2005). In Sweden, the transformation of the role of the father in parenting has been spurred by political interventions since the 1970s (Plantin 2001). Paid parental leave specifically reserved for fathers has shaped and influenced new ideas about how to be a man in Sweden. The dynamic notion of masculinity has also been addressed in the research literature on male sexual assault. A number of studies demonstrate that resilient male survivors of child sexual abuse renegotiate or rebel against masculinity ideals, redefining their perception of manhood and developing a greater range of emotional openness and intimacy (Crete and Singh 2015; Kia-Keating et al. 2005). A study of sexually assaulted males in Ireland has followed a similar path and demonstrates that victims in counselling may choose to adopt an alternative masculinity by resisting stoicism (Forde and Duvvury 2017).

The experience of sexual assault is a subjective, embodied and lived experience. Viewed on the basis of MerleauPonty's work (1962), the body is not the objective body in its materialistic sense but rather the subjective and lived body as experienced by and as yourself. Bodies are attributed properties, such as gender, age and sexuality, based on internalized frameworks and typologies. From a phenomenological perspective (Merleau-Ponty 1962), the body is understood as an active agent in the social world, deeply informed by the sociocultural context in which it is embedded, and intimately interwoven into every social process. Experiences of the past are embodied and remembered, not merely as stored information in the brain, but as a totality of the subject, allowing the individual to respond to present circumstances based on the past (Fuchs 2012). The present study will present results that show how dynamic notions of gender influence the way male victims make sense of their experience of sexual assault over time and also how these gendered experiences are played out in everyday life.

\section{Method}

This qualitative research was conducted by employing an interpretative phenomenological analysis (IPA). The IPA was chosen because it involves a thorough examination of the participants' subjective and lived experience-the meaning they attach to this experience and the way they make sense of what has happened to them, including their emotional responses (Smith et al. 2009). The study explores the most common experiences shared by ten cisgender male adults (straight, gay or bisexual) who have been sexually assaulted.

\section{Participants}

The study participants were primarily recruited by advertising in a Swedish newspaper. The sample of men had experienced severe sexual assault, including completed or attempted anal, vaginal or oral intercourse, penetration with objects, and sexual activity without penetration. These violations had been the result of physical violence or the use of psychological tactics. A number of the men had grown up in violent and disorganized families, which included having witnessed or experienced physical and emotional abuse both inside and outside the home. Table 1 provides some information about the participants and the type of sexual assaults they had experienced.

The ages of the ten participants were relatively evenly distributed, but there is something of a cluster around the age of 50. At the time of the interview, the majority described themselves as middle class, which includes factors such as being in employment, their housing situation and having a good educational background. Seven of the men had postsecondary education (college or university). Six men were in stable co-habiting relationships, while four were single. Eight of the men identified themselves as heterosexual while two identified themselves as homosexual. All the participants had Swedish citizenship, but a few originated from other western European countries.

\section{Data Collection and Analysis}

The data collection in this phenomenological study involved the use of multiple, semi-structured, in-depth interviews. The participants were interviewed on two separate occasions. Each interview lasted approximately $1-2 \mathrm{~h}$ and they took place a week apart. Participants were asked questions about their experiences of sexual assault, how they have responded to these experiences, and how they 
Table 1 Participant details

\begin{tabular}{llll}
\hline Resp. & Age & Time of the assault & Trauma description \\
\hline 1 & $60 \mathrm{~s}$ & Childhood & Physical and sexual abuse by mother and male relatives \\
2 & $50 \mathrm{~s}$ & Childhood & Sexual abuse by a male friend of the family \\
3 & $50 \mathrm{~s}$ & Childhood and adulthood & Physical and sexual abuse by a male headmaster, sexual assault by a male acquaintance \\
4 & $60 \mathrm{~s}$ & Childhood & Physical abuse by parents, physical abuse by male teachers, sexual abuse by a male headmaster \\
5 & $40 \mathrm{~s}$ & Childhood & Sexual abuse by an older brother \\
6 & $70 \mathrm{~s}$ & Childhood and adulthood & Physical abuse by father, sexual abuse by a female caretaker, sexual assault by a female student \\
7 & $50 \mathrm{~s}$ & Childhood & Sexual abuse by a male acquaintance and a male teacher (separate occasions) \\
8 & $30 \mathrm{~s}$ & Adulthood & Physical violence and sexual assault by four male acquaintances (gang rape) \\
9 & $20 \mathrm{~s}$ & Adulthood & Physical violence and sexual assault by a male acquaintance \\
10 & $40 \mathrm{~s}$ & Adulthood & Physical violence and sexual assault by a male partner \\
\hline
\end{tabular}

have affected them in everyday life. Many of the respondents spontaneously shared written material, such as notes, letters, articles, books, poetry and music, which they had produced in response to their experiences of sexual assault. This material was mainly used as background information and as a complement to the in-depth interviews and it was not included in the analysis. All interviews were digitally recorded and transcribed. The data analysis steps involved coding and highlighting sentences or quotations that represent the thoughts and lived experience of the participants. Each case was separately analyzed in detail, and this was followed by a search for repetitions, connections, similarities and differences across all cases (Smith 2011). Clusters of meaning from the quotations were thus developed into themes. Researchers who apply IPA recognize that the lived experience of the participants is not reached in a straightforward manner. Rather, they must engage in a double hermeneutic (Giddens 1987), which means that the researchers interpret the participants' interpretations of what has happened to them (Smith et al. 2009). The narratives of the study participants are intimate, gendered and emotionally charged. The men have presented their memories of a past experience, i.e. a memory that is shaped by the contemporary sociocultural context. In order to reduce possible research biases and to discuss and reflect on our interpretations of the data, both the author and co-author were engaged in the process of analysis. By bringing our different backgrounds, experiences, values and gender perspectives to our analysis and writing, we have been able to reflect on our understandings of the complexity of the narratives and the lived experiences of the study participants. Since both a male and a female researcher have been involved in the analysis, we have been able to explore how notions of gender affect the male victims' understandings of sexual assault from different gendered perspectives.

\section{Ethics}

Research on sexual violence is a sensitive topic as it uncovers painful experiences. During such interviews, participants may disclose information that they rarely address or never share. To minimize harm, participants were well informed about the aim of the study, including the research questions, prior to the interviews. Throughout the study, any signs of discomfort were given a high priority. Information about professional organizations that provide counselling to victims of sexual assault was given to the participants, and these organizations could be contacted in cases of emotional distress following the interviews. During data collection, none of the participants had any serious mental health issues, such as suicidal thoughts, depression or psychosis, and none of them were involved in a violent intimate relationship (exclusion criteria). Participants with recent experiences of sexual assault (i.e. less than 18 months prior to the interviews) were excluded. This time frame was set to ensure that the participants would be ready to talk about their experiences. The participant with the most recent experience was sexually assaulted 5 years prior to the interviews. The research was approved by the Regional Ethical Review Board in Lund, Sweden.

\section{Results}

Four themes emerged from the analysis with regard to how the participants understand, process and articulate their experiences of sexual assault as gendered, embodied and affective subjects: (a) conflicting feelings and difficult conceptualizations, (b) re-experiencing vulnerability, (c) emotional responses and resistance, and (d) disclosure and creativity. The first two themes can be linked to the actual assault 
while the latter two themes concern ways of processing and articulating the experience. The four themes are strongly interwoven. The narratives in the respective themes should not be read as a linear or chronological process that starts with the assault and then looks at the impact it has had over the life course. The embodied experience of sexual assault is not merely an association to an assault that took place at a certain time in one's life, but is rather intimately woven into the participants' existence as a whole.

\section{Conflicting Feelings and Difficult Conceptualizations}

The study participants demonstrated a certain ambivalence when they were asked to define their experience of sexual assault. Only three respondents referred to their experience using the term "rape"-cases which included severe physical violence and forced anal penetration. The majority of men chose to define their experience as sexual assault. One participant explained: "The sexual assault included many different sexual acts, but it was not violent. He did not hold me down. He did not force me in that way" (Resp 2). Other participants also explained how subtle forms of coercion and manipulation in relation to the sexual acts made them uncertain about how to define their experience. Respondent 4 , who was sexually abused by a teacher at a boarding school, explained that he felt worried that if he did not do what the teacher asked, then all the privileges he had and needed to do well in sports would be withdrawn. Another participant drew attention to the use of blackmail: "He said he would tell my partner and family that I was cheating if I did not have sex with him" (Resp 9). The lack of physical violence in relation to the sexual acts made conceptualization difficult for the men.

A frequently addressed topic was the men's conflicting perceptions about their own involvement and responsibility in the assault. One man, who was attracted by gifts provided by the perpetrator, explained: "Afterwards, I was so ashamed by my greediness to get that t-shirt" (Resp 7). Another participant told of how he had enjoyed the attention and physical arousal but simultaneously felt disgusted: "It was a mixed feeling of revulsion and confirmation" (Resp 6). Respondent 2 connects his experience of child sexual abuse to a lack of affection from his parents, saying: "It was not only unpleasant. It was probably fifty-fifty. There was someone who actually touched me physically, and that was nice, but I knew that it was wrong. I should have said no." Defining their experience as sexual assault becomes difficult when the men feel that they let it happen or enjoyed parts of it.

A few participants who were sexually abused in childhood described feelings of being special. Some were treated as special by the perpetrator while others believed they were special because they had acquired more knowledge or special abilities as a result of their early sexualization. Participants reported being proud over their ability to masturbate at an early age-something that their friends had not yet learned. This can be linked to the internalization of norms about male sexuality, which view sexual prowess as positive. Respondent 5 recounted:

When I was 14 or 15 , I used to think that I was special, as I had had sex, which I suppose I had, but I had homosexual sex. I was very pleased with the fact that I was not a virgin, until I realized that it was not that kind of sex you were supposed to have. (Resp. 5)

Like Respondent 5, other participants also revealed that they had realized later on in life that what they had previously interpreted as being special in a good sense, was, on the contrary, something that instead makes them strange, odd or different, thus generating feelings of alienation.

Five men discussed how their experience of sexual assault had prompted them to question their sexual identity. This type of concern was mentioned by both heterosexual and homosexual participants. Respondent 7 explained that the question "Am I gay now?" had worried him for many years, as he knew that being gay was not something that you were supposed to be according to the prevailing gender norms in the context in which he grew up. He continued: "Now I just feel ashamed that I even felt that way about gay men. Sadly enough, I did not know the difference between homosexuals and pedophiles when I was young." These five respondents admitted that they used to be worried about being perceived as gay if people found out about their experience of sexual assault, but stated that these concerns were no longer relevant. On the contrary, all participants emphasized being open towards all genders and sexualities. Respondent 5 even explained that he had tried to be gay at one point in his life, as he thought it would provide a logical explanation for having been sexually assaulted.

All the above quotations show that the context in which the sexual assault took place makes conceptualization difficult, leaving the victims with conflicting feelings such as pleasure and disgust, desire and fear, specialness and deviancy. The study participants rarely perceived the sexual acts as violent but rather focused on the context in which the acts were performed (i.e. how they were performed and by whom). Their conflicting feelings make them question their gender, sexuality and whether they as victims resisted enough.

\section{Re-experiencing Vulnerability}

The majority of the study participants provided various accounts of how they had relived their experience of sexual assault many times during their lives via flashbacks or strong, vivid and emotional memories. Participants said that 
these flashbacks or memories emerged when they saw, heard or smelled something that could be connected to the assault. Respondent 4 described how he had reacted when he saw a group of men wearing similar clothing to the teachers who had abused him sexually or physically:

I was standing on the street waiting for the bus when I saw them. I had not seen such a group of men for maybe 40 years, a group of perhaps 15 men wearing their black clothing down to here [to the ankles] and cummerbunds. My whole body reacted. I could not move, and I had murderous feelings. [...] The point of my story concerns authority. I get pain in my stomach as a result. It is about the structure and the exercise of power within it. It makes me feel sick-the hierarchy-[with] someone disgusting abusing his position of power. (Resp 4)

The group of men that Respondent 4 ran into did not have anything to do with the abuse. However, their appearance triggered memories of difficult times for the respondent. The account reveals that sexual assault is about power, not only in the situation in which the assault took place, but also years after the violation occurred, via the recalling and reliving of the experience. The body remembers past violence as if it were happening again. A number of other study participants made similar references when describing situations in which they had unintentionally run into their perpetrators years after the sexual assault had occurred. Respondent 7 said: "I saw him, to my big surprise, a few years ago. I froze completely. I could not move. All those years didn't matter. I was a child again. Alone, without support, trying to think clearly but unable to do so." This man was not merely experiencing a physical response but also described a sense of transformation. In a split second, he was a child again, standing in front of his perpetrator. Sexual assault is about power, creating a victim that the perpetrator can make shake and sweat by a mere glimpse or a flashback. The victim is reminded of the power relation and the vulnerable situation he experienced, retaining the sense of being defenseless and always vulnerable to potential threats.

This emphasis on the exercise of power in experiences of sexual assault was mainly expressed in cases in which the perpetrator had been male. One man, who had experienced forced sexual intercourse by a female perpetrator, has a different way of understanding the assault:

I was in a very unpleasant situation. I could not act as I wanted to or ward off the attack, mainly because of the situation we were in and the relation I had to her. I could have used physical violence to make her stop, but I did not. I have not felt hurt by the incident even though she used a lot of physical violence. As the years have passed, I have made the incident kind of romantic instead, so that it has become more of a nice experience, not just "I was attacked!" and all that. (Resp 6)

The respondent emphasizes the minimal impact of the sexual assault, even though he recognizes that the sexual activity was coerced and included physical violence. Time is recognized as having an impact on the way the victim conceptualizes the sexual assault. He has chosen to see the violation in more positive terms over the years, coping with the experience by turning it into something positive rather than a violation. While other study participants described sexual violence perpetrated by men as coercive, violent and powerful, this participant is coping with the experience by feeling flattered by the incident in accordance with norms of male sexuality.

\section{Emotional Responses and Resistance}

The majority of study participants spoke at length about how they have developed a certain sensitivity following their experience of sexual assault. Respondent 3 clarifies this further:

I react very strongly when I see violence. I hate physical violence. I do not want to see people or animals exposed to violence. It has to do with the fact that I feel their vulnerability. Even in war, I feel their insecurity, loneliness, powerlessness and the violence. (Resp. 3)

In a similar way, all the respondents described how, over the years, they have opposed or taken an active stance against violence in various ways. Seeing other people or animals exposed to violence and injustice becomes a reminder of one's own experience, meaning that one can easily feel the pain and vulnerability in that situation oneself. Several men also described having developed something like a sixth sense based on their lived experience. Respondent 10 explained: "I have become totally oversensitive, even allergic you might say. I see and feel violence, pedophiles and hypersexual men from miles away. I react instantly and long before other people even notice." Lived experience means being familiar with an incident and immediately recognizing the characteristics of the complicated situation. Being oversensitive may result in always being on the lookout for dangers, which many of participants reported. It may also result in anger and outbursts of rage. In fact, half of the participants described anger as an emotion that affects their way of acting in the world and their relationships with other people. Others described their anger as something that has vanished over the years, gradually becoming transformed into sorrow. According to Respondent 4, anger has played a major role in how he has felt and acted in his life, and he mentioned feeling homicidal rage (related in an earlier quotation) when he saw a group of men wearing similar clothing to that which 
the perpetrators had worn. Respondent 4 related his anger to the power structures in which he grew up, to the feeling of being powerless in what he described as patriarchal structures, and the culture of men. Respondent 3 described the same reasoning as underlying his actions:

When I was around twenty, I lived out all the aggressions I had accumulated at school. I became very rebellious. I was already institutionally damaged, meaning that I was not afraid of being caught by the police. I was not afraid of being punished anymore. I still have a need to annoy authorities, but nowadays I do it verbally instead. (Resp 3)

Four participants, including Respondents 3 and 4, reported that they had become involved in criminal activity when they were younger as a way of acting out the anger that they felt in relation to the powerless situation they had experienced when they were sexually assaulted. They reported having been involved in stealing and crashing cars, selling alcohol and drugs illegally, and also in reckless driving, robbery and violence. Two participants also reported turning their anger against themselves, among other things in the form of suicidal thoughts and self-injury. A few have spent time in prison for the crimes they have committed, but most of the study participants did not end up as criminals despite their early involvement in such activities. Respondent 3 still reacts against and resists his experience of physical and sexual violence, using words instead of criminal activities. However, Respondent 4 explained that, despite having a good and prosperous life, he still feels the need to shoplift. He regularly steals petty things, like cookies at an expensive or fancy café that he may dislike, simply in order to resist and oppose the structures of power.

Some participants did not recognize themselves as angry at all but still pointed out that they have problems with authorities and certain types of power relations. In fact, as many as seven participants described that they repeatedly or during certain periods of their lives have ended up in conflicts with colleagues and managers at work. Many participants described similar experiences to those of Respondent 2:

I have conflicts and disagreements with my bosses and male authorities, and I react intensely. I am very vulnerable, easily offended, and I respond negatively to criticism. Men in positions of power-I still have problems with that sometimes, in particular those manly men in their fifties. (Resp 2)

The above description points to how study participants sensitize and respond to unbalanced power relations in everyday life. The men who were sexually assaulted by other men specifically referred to patriarchal structures and the culture of masculinity as extremely provocative. Respondent 7 stated: "I could have been a male chauvinist like many in my surroundings, but I am not. I am so grateful because the experience of sexual abuse has opened my eyes and my perspective." The men in the study are able to talk about the heavy toll the experience of sexual assault has had on their lives, describing how they display feelings such as anger, sadness, empathy, vulnerability and anxiety. They are also able to reflect on how their experiences have changed their worldviews and gender perspectives in a more positive way.

\section{Disclosure and Creativity}

All the study participants had disclosed their experience of sexual assault to families and friends, but deeper conversations were said to be avoided generally. They related this to their feelings of embarrassment or shame, which were rooted in the intimidating nature of the violation and the conflicting perceptions about their own involvement and responsibility in the assault. One participant said: "I mentioned it to my wives, but I have spared them the details" (Resp 6). Similarly, the other participants reported simply mentioning their experience, avoiding details and feelings in situations involving face-to-face interactions. One man explained: "I do not have a problem talking about what happened nowadays, but people react differently when they hear about male rape, and that can sometimes be extremely hurtful" (Resp 8 ). Perceived or actual social responses are key to understanding why the study participants tend to avoid disclosure. The majority of men also described difficulties in accepting being perceived as a victim, in terms of an identity. One participant clarified this in the following way: "I am not a victim, and I do not want to be looked at as if I am a victim. Therefore, I do not talk about it generally, only with people who have knowledge about these issues, like professionals and researchers" (Resp 9). Being seen as a powerless victim of sexual violence is particularly difficult for men, as this transgresses conventional norms of masculinity. Like many other participants, Respondent 9 resists victimhood by refusing to talk about the traumatic experience with those around him. Instead, he relays his experience only to those who are able to comprehend the narrative, such as professionals.

During the interviews, a number of the men tended to minimize the severity of their own victimization by drawing attention to, comparing and referring to other people's experiences of sexual assault. Both Respondents 1 and 3 spoke at length about how their younger brothers had suffered from various forms of extreme violence, both physical and sexual. Respondents 4 and 7 referred to the famous Swedish former high jumper Patrik Sjöberg's ${ }^{1}$

\footnotetext{
${ }^{1}$ Patrik Sjöberg is a former world record holder in the high jump. In an autobiography published in 2011, Sjöberg revealed his experience of the childhood sexual abuse perpetrated by his stepfather, who was also his athletics coach.
} 
experiences of child sexual abuse as being far worse than their own experience. Mitigating the seriousness of one's own experience of sexual assault may be a way of coping with difficult or painful memories or of avoiding or denying personal experiences. Sensitizing other people's exposure to violence also constitutes a show of empathy.

Four of the study participants revealed that they turned to therapy in an effort to understand and process their experience and to improve their psychosocial well-being. Most of the men also relied on various forms of self-care strategies, which all came in the form of artistic expression. Three men articulated their experience by writing books, poetry, manuscripts or diaries and notes. Four other participants have composed music to help them understand their experience and express their emotions in relation to it. Respondent 1 described this as follows:

My lyrics and my music guided me to remember my suppressed experience. I was able to formulate my experience symbolically through music. First, unconsciously, I did not understand what was going on. I kept the songs to myself initially; I did not want to expose them publicly. Later on, I was amazed by people's positive responses to the emotional messages in the songs. Music and composing became my free zone. (Resp 1)

Here, creativity is a response to difficult circumstances. Like Respondent 1, other study participants also described creativity as a way of both escaping from and seeking solutions to the pain and distress caused by the traumatic experience. Creativity is a way of trying to understand and articulate the experience without necessarily revealing the exact content of the experience to others; but more importantly, it is a way of expressing emotions. Respondent 4 explained that his poetry, with its focus on issues of war and political instability on a global scale, actually conceals memories of his childhood, since he grew up in an environment characterized by various forms of physical, emotional, political and sexual violence. By writing poetry and working professionally with issues of violence, Respondent 4 is processing his memories in his own way. Respondent 3 reported: "Creating music became my way of reaching out to other people and to society more generally. By writing provocative songs about authorities, I could express, or even avenge, my personal and subjective experience." The study participants use their creativity as a way to express emotions and resist power, violence, and norms of masculinity. Thus, they receive confirmation from others and feel less powerless as they take back at least parts of what they once lost. The men described this as a long but worthwhile process, emphasizing that they all feel much better today than previously.

\section{Discussion}

The aim of this phenomenological research project was to understand how men make sense of their experiences of sexual assault as gendered, embodied and affective subjects. By focusing on men's engagement with norms of masculinity, the findings provide a nuanced picture of how men understand, process and articulate their lived experience. The findings demonstrate that embodied experience of sexual assault is a dynamic, rich and complex psychosocial process that takes place in interaction with the self, others and society at large. The history of sexual assault remains present in the lives of the victims through body memory, while dynamic notions of gender strongly shape and influence the victims' lived bodily engagements and negotiations over time.

Previous research has recognized that male victims of sexual assault experience self-blaming attitudes and conflicting thoughts about their masculinity and sexuality (Davies 2002; Mezey and King 1989; Struckman-Johnson and Struckman-Johnson 1994; Tewksbury 2007; Walker et al. 2005). This is also evident in the findings from the present study, with the participants reporting difficulties in conceptualizing the sexual assault based on their expectations and ideas about what such violations should or should not include. Conflicting feelings, such as pleasure and disgust, desire and fear, specialness and deviancy, innocence and guilt, have a profound impact on the victims (cf. Alaggia and Millington 2008). The narratives demonstrate the dynamics of this confusing process by illuminating the way sexual assault is interpreted and reinterpreted over time. One example of this concerns the participants who realized that they were not the special person they had thought they were as a result of their early sexualization. Others who had enjoyed some parts of the sexual assault explained that they had gradually understood that they were victims of what is today considered to be one of the most terrible crimes one can be exposed to. Thus, the participants clarified how an experience in the past can be re-experienced and re-interpreted in new contexts or in the light of new knowledge. The actions performed many years ago may be seen as actions of a new kind. Thus, the way the participants understand their experience of sexual assault changes over time. The victims deal with their experience in a changing world by positioning and repositioning the self in relation to that world (Hacking 1999). In this process, the men also negotiate and renegotiate norms of masculinity.

Studies have suggested that men and women experience violence from different power and gender relations (Draucker 2003; Getz 2011; Sundaram et al. 2004). Existing literature demonstrates that sexually assaulted men 
find it particularly difficult to accept victimhood (O'Leary and Barber 2008). This is understandable because, according to widespread and culturally accepted norms of masculinity in western contexts, men are expected to be powerful, dominant, fearless, aggressive, stoic, virile and potent, which are attributes by which men assert power over one another (Connell 1995). Thus, experiencing sexual assault is the antithesis of these ideas of masculinity. The men in the current study described the experience of male power, domination and control as particularly intimidating, disturbing and threatening. In fact, the experience of the exercise of such power becomes inscribed into the body memory and is re-experienced many times throughout the life course (Fuchs 2012). The power and control of the male perpetrator damaged the male victims' own sense of power and control, challenging their notions of self. The study participants described not only how they lost themselves in confusing conceptualizations and conflicting ideas and feelings related to the violation but also how they lost their sense of being able to defend themselves, which made them highly sensitive to imbalanced, unequal and gendered interpersonal relationships and potential dangers in everyday life. In the process of understanding and making sense of their confusion, vulnerability and sensitivity, the study participants had to confront and negotiate their masculine identity. In doing this, the sexually assaulted men had to both engage with conventional masculine ideals and avoid being affected by the characteristics and experiences that stand in contrast to these ideals (Kia-Keating et al. 2005).

The findings reveal not only that the study participants were challenged by conventional masculine ideals, and in particular those related to anger, violence, sexuality, sexual identity and stoicism, but also how these ideals were renegotiated. Anger and violence may be a culturally acceptable way for men in western contexts to express emotions (Connell 2000), and the literature identifies anger and violence as a common response to sexual assault among men (Tewksbury 2007). The men in the present study recognized anger as a common emotional response to their experience but mainly emphasized that they used to be aggressive and violent when they were younger. At the time of the interviews, the majority of participants described feeling disgusted by violence and that they engaged in various forms of anti-violent activities. The existing literature identifies homophobia as having a profound impact on the way sexually assaulted men think of themselves as gendered and sexual beings (Davies 2002; Mezey and King 1989; Walker et al. 2005). The study participants described that they used to be worried about not being heterosexual but also explained that they had shifted to more liberal and open ideas of gender and sexuality, embracing pro-gay attitudes. The men in the current study were also challenged by ideas of stoicism, which can be seen in the way they reaffirmed their masculinity by trying to avoid disclosure or by minimizing and trivializing the severity of their experience. However, the majority of the men had found creative ways of processing, displaying and articulating their emotions. Research shows that there are diverse and gendered ways of expressing emotional experiences, and that some men use music in particular as a way to deal with emotions (de Boise 2016). The production of music, art or literature can be seen as one of the few culturally accepted spheres in which men are allowed and expected to express and share their emotions. Most of the study participants embraced this sphere of artistic expression as a form of self-help to understand, process and articulate their experience and to heal. Several of the study participants who express themselves artistically described this as a sphere in which they are free to be emotional and to resist injustice and unequal power relations. The participants both processed and resisted their experiences of sexual assault years after the violations had occurred by gradually adopting an alternative masculinity. This is consistent with other findings which suggest that the renegotiation of masculinity (i.e. both the maintenance and resistance of conventional masculine ideals) is an important process for victims in healing from a traumatic past (Crete and Singh 2015; Forde and Duvvory 2017; Kia-Keating et al. 2005).

Therapy for victims of sexual assault and other forms of violence can be characterized as a process in which the therapist identifies and treats the harmful effects of the experience. In this regard, both the clinical and research literature on the negative psychological impacts of male sexual assault perceives the body as a biological fact, and as reacting to a specific stimulus in the environment. When focusing on the psychological impacts of violence, this field of research often talks about the men rather than conceptualizing them as active and subjective agents who are responding to their social context based on their lived experience. According to response-based therapy (Wade 1997), individuals do not react to violence according to a set of pre-established patterns. When individuals are distressed, researchers and therapists can reach an understanding of that distress by listening to how the individuals respond to their subjective experience (Wade 1997). In this process, engaging clients in conversations about the nature of their resistance against violence has proven useful, as it helps the clients see that they are not passive, helpless and vulnerable victims (i.e. that they did not just let it happen and that they were not lacking in boundaries or self-esteem and are therefore not to blame for the assault) (Renoux and Wade 2008). Forms of resistance depend on various factors, such as the historical and sociocultural context, the circumstances of a given setting and the relationship between the people involved in the violence. This study demonstrates that dynamic notions 
of gender inform the way men make sense of their experiences of sexual assault, including their responses. The men in the study responded to their experience of sexual assault by resisting a restricted emotionality (i.e. they became angry, sad, anxious, oversensitive or extremely alert and cautious, and used creative outlets to reach and express emotions). They responded to their experiences by resisting victimhood and by avoiding deeper face-to-face conversations in everyday life about what had happened to them. Victims of sexual assault can be supported by counselling that focuses on responses, but it should also include the provision of support on how to deconstruct the gender system of which the victims are a part (Kia-Keating et al. 2005; Lisak 1995). Whether men are victims of child sexual abuse or adult sexual assault, helping them to identify their responses and resistance to violence, and the role gender plays in the process of understanding sexual assault, will enable them to make sense of their experience, to gain control over it and to improve their well-being.

The findings of this study are limited by the relatively small sample size, which is adequate for the purposes of IPA (Smith 2011). However, a larger and more diverse sample, including transgendered and gender nonconforming persons and participants with various religious, cultural and ethnic backgrounds would be desirable to make comparisons. The current findings should be understood in relation to the specific cultural context in which the participants live their everyday lives. A bias can be noted in the sample, as the study participants tended to represent a more reflective and culturally expressive kind of man who actively seeks solutions to improve his well-being.

\section{Conclusion}

The narratives provided in this article extend our understanding of how men make sense of their experience of sexual assault. Despite many years having passed since the men's assaults took place, their experiences remain present in everyday life through flashbacks and strong emotional memories. The history of sexual assault is an ongoing issue that challenges the sexually assaulted men in various ways. In order to live with their embodied experience, the victims must find ways to endure it. By both engaging with and contesting conventional masculine ideals, the study participants have adopted an alternative masculine identity. This alternative masculinity stands in stark contrast to the masculine attributes that the victims assign to their perpetrators. Dynamic notions of masculinity thus play an important role for the health and well-being of the male victims of sexual assault.
Acknowledgements The authors would like to thank the participants in this study for sharing their life stories, insights and perspectives.

Funding This study was funded by The Swedish Crime Victim Compensation and Support Authority (Brottsoffermyndigheten).

\section{Compliance with Ethical Standards}

Conflict of interest The authors declare that they have no conflict of interest.

Ethical Approval All procedures in studies involving human participants were in accordance with the ethical standards of the institutional and/or national committee and with the 1964 Helsinki declaration and its later amendments or comparable ethical standards. The research was approved by the Regional Ethical Review Board in Lund, Sweden.

Informed Consent Informed consent was obtained from all participants included in the study.

OpenAccess This article is distributed under the terms of the Creative Commons Attribution 4.0 International License (http://creativeco mmons.org/licenses/by/4.0/), which permits unrestricted use, distribution, and reproduction in any medium, provided you give appropriate credit to the original author(s) and the source, provide a link to the Creative Commons license, and indicate if changes were made.

\section{References}

Alaggia, R., \& Millington, G. (2008). Male childhood sexual abuse: A phenomenology of betrayal. Clinical Social Work Journal, 36, 265-275. https://doi.org/10.1007/s10615-007-0144-y.

Anderson, E. (2005). Orthodox and inclusive masculinity: Competing masculinities among heterosexual men in feminized terrain. Sociological Perspectives. 48(3), 337-355. https://doi.org/10.1525/ sop.2005.48.3.337.

Brottsförebyggande Rådet (Brå). (2018). Kriminalstatistik 2017. Anmälda brott. Stockholm: Brå. Retrieved from https://bra.se/ download/18.10aae67f160e3eba62938177/1522141587204/ Sammanfattning_anmalda_2017.pdf.

Brownmiller, S. (1975). Against Our Will. New York: Simon \& Schuster.

Callaghan, J. E. M., Alexander, J. H., \& Fellin, L. C. (2016). Children's embodied experience of living with domestic violence: "I'd go into my panic, and shake, really bad. Subjectivity, 9(4), 399-419. https://doi.org/10.1057/s41286-016-0011-9.

Clark, J. N. (2017). Masculinity and male survivors of wartime sexual violence: A Bosnian case study. Conflict, Security \& Development, 17(4), 287-311. https://doi.org/10.1080/14678802.2017.1338422.

Connell, R. W. (1995). Masculinities. Cambridge: Polity Press.

Connell, R. W. (2000). The men and the boys. Berkeley: University of California Press.

Connell, R. W. (2005). Growing up masculine: Rethinking the significance of adolescence in the making of masculinities. Irish Journal of Sociology. 14, 11-28. https://doi.org/10.1177/07916 0350501400202.

Crete, G. K., \& Singh, A. A. (2015). Resilience strategies of male survivors of childhood sexual abuse and their female partners: A phenomenological inquiry. Journal of Mental Health Counseling, 37, 341-354. https://doi.org/10.17744/mehc.37.4.05. 
Davies, M. (2002). Male sexual assault victims: A selective review of the literature and implications for support services. Aggression and Violent Behavior, 7, 203-214. https://doi.org/10.1016/S1359 -1789(00)00043-4.

de Boise, S. (2016). Contesting 'sex' and 'gender' difference in emotions through music use in the UK. Journal of Gender Studies, 25(1), 66-84. https://doi.org/10.1080/09589236.2014.894475.

Dobash, R. E., \& Dobash, R. P. (1979). Violence against wives: A case against the patriarch. New York: Free Press.

Draucker, C. B. (2003). Unique outcomes of women and men who were abused. Perspectives in Psychiatric Care, 39(1), 7-16.

Dube, S. R., Anda, R. F., Whitfield, C. L., Brown, D. W., Felitti, V. J., Dong, M., \& Giles, W. H. (2005). Long-term consequences of childhood sexual abuse by gender of victim. American Journal of Preventive Medicine, 28(5), 430-438. https://doi.org/10.1016/j. amepre.2005.01.015.

Fergusson, D., Lynsky, M., \& Horwood, I. (1996). Childhood sexual abuse and psychiatric disorder in young adulthood: I. Prevalence of sexual abuse and factors associated with sexual abuse. Journal of the American Academy of Adolescent Psychiatry, 35, 13551364. https://doi.org/10.1097/00004583-199610000-00023.

Forde, C., \& Duvvury, F. (2017). Sexual violence, masculinity, and the journey of recovery. Psychology of Men \& Masculinity, 18(4), 301-310. https://doi.org/10.1037/men0000054.

Freeland, R., Goldenberg, T., \& Stephenson, R. (2016). Perceptions of informal and formal coping strategies for intimate partner violence among gay and bisexual men. American Journal of Men's Health, 12(2), 302-312. https://doi.org/10.1177/1557988316631965.

Fuchs, T. (2012). The phenomenology of body memory. In S. C. Koch, T. Fuchs, M. Summa \& C. Muller (Eds.), Body memory, Metaphor and Movement. Amsterdam: John Benjamins Publishing Company.

Getz, L. (2011). Male survivors of childhood sexual abuse: Looking through a gendered lens. Social Work Today, 11(2), 20.

Giddens, A. (1987). Social Theory and Modern Sociology. Cambridge: Polity Press.

Hacking, I. (1999). The Social Construction of What? Cambridge: Harvard Univ. Press.

Kelly, L. (1988). Surviving Sexual Violence. Minneapolis: University of Minnesota Press.

Kia-Keating, M., Grossman, F., Sorsoli, F., \& Epstein, M. (2005). Containing and resisting masculinity: Narratives of renegotiation among resilient male survivors of childhood sexual abuse. Psychology of Men \& Masculinity, 6(3), 169-185. https://doi. org/10.1037/1524-9220.6.3.169.

Krahé, B., Scheinberger-Olwig, R., \& Bieneck, S. (2003). Men's reports of nonconsensual sexual interactions with women: Prevalence and impact. Archives of Sexual Behavior, 32, 165-175. https ://doi.org/10.1023/A:1022456626538.

Kwon, I., Lee, D. O., Kim, E., \& Kim, H. Y. (2007). Sexual violence among men in the military in South Korea. Journal of Interpersonal Violence. 22, 1024-1042. https://doi.org/10.1177/08862 60507302998.

Larsen, M., \& Hilden, M. (2016). Research paper: Male victims of sexual assault; 10 years' experience from a Danish Assault Center. Journal of Forensic and Legal Medicine, 43, 8-11. https://doi. org/10.1016/j.jflm.2016.06.007.

Lisak, D. (1995). Integrating a critique of gender in the treatment of male survivors of childhood abuse. Psychotherapy, 32, 258-269. https://doi.org/10.1037/0033-3204.32.2.258.

McQueen, F. (2017). Male emotionality: 'Boys don't cry' versus 'it's good to talk.'. NORMA: International Journal for Masculinity Studies, 12(3-4), 205-219. https://doi.org/10.1080/18902 138.2017.1336877.

Merleau-Ponty, M. (1962). Phenomenology of perception. London: Routledge.
Messerschmidt, J. W. (1999). Making bodies matter: Adolescent masculinities, the body and varieties of violence. Theoretical Criminology, 3, 197-220. https://doi.org/10.1177/136248069900300 2004.

Mezey, G., \& King, M. (1989). The effects of sexual assault on men: A survey of 22 victims. Psychological Medicine, 19, 205-209. https ://doi.org/10.1017/S0033291700011168.

Mouilso, E. R., Calhoun, K. S., \& Gidycz, C. A. (2010). Effects of participation in a sexual assault risk reduction program on psychological distress following revictimization. Journal of Interpersonal Violence, 26(4), 769-788. https://doi.org/10.1177/08862 60510365862.

Nationellt Centrum för Kvinnofrid (NCK). (2014). Våld och Hälsa: En befolkningsundersökning om kvinnors och mäns våldsutsatthet samt kopplingen till hälsa. Uppsala: NCK-rapport. Uppsala Universitet.

O'Leary, P. J., \& Barber, J. (2008). Gender differences in silencing following childhood sexual abuse. Journal of Child Sexual Abuse, 17, 133-143. https://doi.org/10.1080/10538710801916416.

Pegram, S. H., \& Abbey, A. (2016). Associations between sexual assault severity and psychological and physical health outcomes: Similarities and differences among African American and Caucasian Survivors. Journal of Interpersonal Violence. https://doi. org/10.1177/0886260516673626.

Peterson, Z., Voller, E., Polusny, M., \& Murdoch, M. (2011). Prevalence and consequences of adult sexual assault of men: Review of empirical findings and state of the literature. Clinical Psychology Review, 31, 1-24. https://doi.org/10.1016/j.cpr.2010.08.006.

Plantin, L. (2001). Män, familjeliv och föräldraskap. Umeå: Borea bokförlag.

Rafanell, I., McLean, R., \& Poole, L. (2017). Emotions and hyper-masculine subjectivities: The role of affective sanctioning in Glasgow gangs. NORMA: International Journal for Masculinity Studies, 12(3-4), 187-204. https://doi.org/10.1080/18902138.2017.13129 58.

Ratner, P. A., Johnson, J. L., Shoveller, J. A., Chan, K., Martindale, S. L., Schilder, A. J., \& Hogg, R. S. (2003). Non-consensual sex experienced by men who have sex with men: Prevalence and association with mental health. Patient Education and Counseling, 49, 67-74. https://doi.org/10.1016/S0738-3991(02)00055-1.

Renoux, M., \& Wade, A. (2008). Resistance to violence: A key symptom of chronic mental wellness. Context, 98, 2-4.

Scarce, M. (1997). Same-sex rape of male college students. Journal of American College Health, 45(4), 171-173. https://doi. org/10.1080/07448481.1997.9936878.

Scott, J. (1990). Domination and the Arts of Resistance. New Haven: Yale University Press.

Sivakumaran, S. (2007). Sexual violence against men in armed conflicts. The European Journal of International Law, 18(2), 255276. https://doi.org/10.1093/ejil/chm013.

Smith, J. A. (2011). Evaluating the contribution of interpretative phenomenological analysis. Health Psychology Review, 5(1), 9-27. https://doi.org/10.1080/17437199.2010.510659.

Smith, J. A., Flowers, P., \& Larkin, M. (2009). Interpretative phenomenological analysis: Theory, method, research. London: Sage.

Struckman-Johnson, C., \& Struckman-Johnson, D. (1994). Men pressured and forced into sexual experience. Archives of Sexual Behavior, 23, 93-114. https://doi.org/10.1007/BF01541620.

Sundaram, V., Helweg-Larsen, K., Laursen, B., \& Bjerregaard, P. (2004). Physical violence, self rated health, and morbidity: Is gender significant for victimisation? Journal of Epidemiol Community Health, 58, 65-70. https://doi.org/10.1136/jech.58.1.65.

Tewksbury, M. (2007). Effects of sexual assaults on men: Physical, mental and sexual consequences. International Journal of Men's Health, 6(1), 22-35. 
Turchik, J. A., \& Edwards, K. K. (2012). Myths about male rape: A literature review. Psychology of Men \& Masculinity, 13(2), 211-226. https://doi.org/10.1037/a0023207.

Wade, A. (1997). Small acts of living: Everyday resistance to violence and other forms of oppression. Contemporary Family Therapy, 19, 23-39.

Walker, J., Archer, J., \& Davies, M. (2005). Effects of rape on men: A descriptive analysis. Archives of Sexual Behavior, 34, 69-80. http://psycnet.apa.org/doi/https://doi.org/10.1007/s1050 8-005-1001-0.

Wooden, W., \& Parker, J. (1982). Men behind bars: Sexual exploitation in prison. New York: Da Capo Press.

World Health Organization (WHO). (2013). Global and regional estimates of violence against women: Prevalence and health effects of intimate partner violence and non-partner sexual violence. Geneva: WHO.

Yuan, N., Koss, M., \& Stone, M. (2006). The psychological consequences of sexual trauma. Harrisburg, PA: VAWnet. Retrieved from https://vawnet.org/sites/default/files/materials/files/2016-09/ AR_PsychConsequences.pdf.
Publisher's Note Springer Nature remains neutral with regard to jurisdictional claims in published maps and institutional affiliations.

Charlotte C. Petersson holds a Ph.D. in Social Anthropology from the University of Gothenburg. Her work focuses on sexual health and gender violence in international settings. She is affiliated with the Centre for Sexology and Sexuality Studies at the Department of Social work, Malmö University, Sweden.

Lars Plantin is a professor in Social work at Malmö University, Sweden. He works at the Centre for Sexology and Sexuality Studies and is currently conducting research on men and sexual abuse, sexual consent and sexual and reproductive rights among persons who sell sex. 